\title{
Ensaio
}

\section{Da arqueologia da mídia às ficções teóricas. Um giro reflexivo}

Fabrício Silveira ${ }^{1}$

\section{Resumo}

Trata-se de um ensaio, no sentido mais literal do termo. O texto expõe os bastidores de um processo de pesquisa. Formula, fundamentalmente, a transição de um interesse genérico pelo campo da arqueologia das mídias para o campo mais singularizado das ficções teóricas, tal como subentendidas pelo filósofo e crítico cultural inglês Mark Fisher. Essa transição, no entanto, não implica um abandono nem uma adoção abruptos, extemporâneos. Antes, o que ocorre é um ajuste de foco, a elaboração de uma certa transversalidade e de uma comensurabilidade entre as duas perspectivas.

Palavras-chave: Arqueologia da mídia. Ficções teóricas. Pesquisa em Comunicação.

\begin{abstract}
It is an essay, in the most literal sense of the word. The text exposes the background of a research process. It fundamentally formulates the transition from a generic interest in the field of media archeology to the more singular field of theory fictions, as defined by the English philosopher and cultural critic Mark Fisher. This transition, however, does not imply an abrupt, extemporaneous abandonment or adoption. Rather, what happens is an adjustment of focus, the elaboration of a certain transversality and commensurability between the two perspectives.
\end{abstract}

Keywords: Media archeology. Theory fictions. Communication research.

Elaborei uma lista de tópicos que gostaria de discutir. Tenho em vista o processo de dinamização e aperfeiçoamento permanente de meu projeto de investigação. Isso se justifica também enquanto exercício de modulação, de favorecimento de um encaixe (desse projeto) num quadro mais amplo de estudos correlacionados, em etapas variáveis de

\footnotetext{
1Doutor em Ciências da Comunicação (Unisinos). Pós-Doutor pela School of Arts and Media (Salford University, UK). Atualmente, realiza estágio pós-doutoral - bolsa PNPD Capes - junto ao Programa de Pós-Graduação em Comunicação da UFRGS. Formado em Comunicação Social habilitação em Jornalismo pela UFSM. Mestre em Comunicação e Informação (UFRGS). fabriciosilveira@terra.com.br
} 


\section{VOZES $_{\text {\&IÁLORO }}^{\mid}$}

Itajaí, V. 20, n.01, jan-jun 2021

maturação e acabamento (no caso, o próprio grupo de pesquisa do qual participo) ${ }^{2}$. Os tópicos em lista não se encontram "sistematizados" - isto é, não foram pensados dentro de uma ordenação muito rígida ou desde um lugar epistemológico que lhes atribua unidade ou algum outro tipo de coerência exterior. Não foram pensados dentro de uma arquitetura previamente definida. $\mathrm{O}$ que lhes dá alguma coesão é o fato de pertencerem ao espaço de abrangência de um mesmo documento: o plano de pesquisa ao qual se reportam. É também o fato de estarem agora agrupados num único relato e terem sido escritos pelo mesmo autor (pela mesma "função-autor", eu poderia dizer, ou por um mesmo “responsável jurídico”).

Em realidade, abrem-se aqui, sem muitas preocupações, como veremos, questões epistêmicas, questões teóricas, questões de mera formalidade e problemas metodológicos, atinentes, dentre outros, à montagem de um corpus empírico e à reelaboração de um foco. Em razão disso, o que teremos é um texto elíptico, sem buscar aprofundamentos de nenhum tipo, desamparado de certezas e entregue ao próprio processo de se construir em público, obtendo, a partir daí, não apenas transparência mas, junto dela, as condições essenciais de sua própria (e ainda precária) cientificidade.

Na rotina de um trabalho de pesquisa, esses enfrentamentos - em diferentes níveis, tais como aqueles que mencionei há pouco - se dão em simultâneo, como se constituíssem uma grande mistura de problemas indistintos e mutuamente relacionados. É esse aspecto caótico - típico, aliás, da experiência de um pesquisador - que procurarei aqui preservar.

Diante disso, não se trata de aparentar racionalidade, formular respostas (ou mesmo novas e melhores perguntas) aparentemente sensatas ou simular um controle que, a bem da verdade, nem sempre se tem. Não é o caso, nem mesmo, de enrijecer o projeto de pesquisa que nos orienta, como se a prática concreta da investigação se deixasse depreender como um decalque, como se estivesse já prevista, à espera de uma ativação, no registro inicial do qual partimos. A pesquisa está viva, todos nós sabemos disso. O que pretendo é registrar um pouco dessa vivacidade, um momento muito singular num mesmo contínuo de palpitações. E “palpitações” - é quase desnecessário dizê-lo - é uma metáfora suficientemente abrangente, uma ótima metáfora, diga-se de passagem, um grande guardachuva semântico sob o qual se acomodam as incertezas, os acautelamentos, as hipóteses e as novas possibilidades que vão entrando e saindo de cena, o tempo todo.

\footnotetext{
2 O artigo foi produzido com o propósito inicial de ser apresentado, no dia 22 de outubro de 2020, numa das reuniões do grupo de pesquisa Corporalidades, liderado pela profa. Dra. Nísia Martins do Rosário, junto ao Programa de Pós-Graduação em Comunicação da Universidade Federal do Rio Grande do Sul. Esse endereçamento - para um fórum restrito de pesquisadores, um espaço laboratorial, de trocas e orientações coletivas, de promoção de convergências abertas e responsáveis - explica, em boa medida, o tom adotado: a narrativa em primeira pessoa (com oscilações), o caráter processual, talvez excessivamente aberto, próximo à confissão e ao informe noticioso. Acredito que essa entonação é muito útil à pedagogia do trabalho científico. Será mantida aqui em razão disso.
} 


\section{VOZES $_{\text {\&IÁLORO }}^{\mid}$}

Itajaí, V. 20, n.01, jan-jun 2021

\section{1.}

Antes de avançar no primeiro ponto, gostaria de propor um breve panorama teórico.

O campo da arqueologia das mídias - ao qual me encontro filiado, como sócio inadimplente, todos entenderão - é um campo heterogêneo e multifacetado. Nesse cenário, para início de conversa, cabe salientar a importância inegável de 1) Friedrich Kittler, nascido na Alemanha (1943-2011), dedicado ao exame das mídias como sistemas de notação, como tecnologias de guerra (ou derivadas das tecnologias bélicas, da inteligência militar), dedicado à história da literatura, do alfabeto e da Grécia antiga; 2) Siegfried Zielinski, também alemão, nascido em 1951, com discussões marcantes sobre o tempo profundo da mídia, sobre variantologia como perspectiva teórico-metodológica, sobre as noções de "entr'acts" e psycopathia medialis; 3) Wolfgang Ernst, outro teórico alemão, nascido em 1959, que desenvolve o que chama de arqueografia ou arqueologia metamedial, preocupado com "entidades não-discursivas" e "equiprimordiais”, com memórias e arquivos digitais e analógicos; 4) Eric Kluitenberg, um jovem holandês, nascido em 1965, atento às mídias imaginárias, às relações de força entre discursividade/narratividade/fantasia, às mídias em potência (ou sonhadas) e às mídias enquanto projeto utópico; e 5) Thomas Elsaesser, alemão baseado na Holanda (19432019), muito reconhecido como teórico do cinema, para quem a arqueologia das mídias é um projeto relacional vetorizado pelo cinema como "arche" - quer dizer, o cinema como

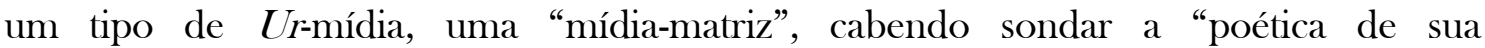
obsolescência” ou mesmo a cinefilia como necrofilia. Nesse panorama, 6) o finlandês Jussi Parikka é outro autor de destaque entre os expoentes do campo. Parikka está para os estudos mídia-arqueológicos como Umberto Eco está para os estudos semióticos: como um curinga, um grande mercador, responsável por desbravar uma infinidade de frentes inéditas e instigantes: a geologia das mídias, as mídias zumbi (o circuit bending e outras explorações de artemídia) e os vírus de computador.

Pois bem.

O primeiro ponto que gostaria de destacar diz respeito a um impasse. Em março de 2019, quando dei início à pesquisa de pós-doutorado, meu projeto derivava de um projeto anterior, iniciado e interrompido, bruscamente, em 2018 (iniciado em março, interrompido em dezembro de 2018). O que propus, com ajustes, com novos reenquadramentos e com novo dimensionamento de fôlego, foi dar continuidade - noutra universidade e noutro regime de trabalho - a um mapeamento teórico-monográfico do campo da arqueologia das mídias no Brasil.

Em poucas palavras: me importava rastrear os distintos veios mídia-arqueológicos - como elencamos acima, rapidamente -, reconhecer seus pressupostos teóricos, seus contextos de fundação, seus métodos e seus objetos preferenciais, e enxergá-los depois 


\section{VOZES $_{\text {\&IÁLORO }}^{\mid}$}

Itajaí, V. 20, n.01, jan-jun 2021

refletidos na produção brasileira, num período compreendido entre 2000 e 2020, aproximadamente. Era um recorte arbitrário, sem dúvida, proposto com antecipação ao manejo efetivo do material bibliográfico, projetando obter viabilidade e suficiente representatividade qualitativa.

A partir daí, poderíamos responder às seguintes perguntas: como essa(s) matriz(es) teórica(s) - posicionadas no panorama já sugerido - se instalam entre nós?; como chegam até nós?; como se manifestam essas tendências?; como são internalizadas?; como circulam?; a que (temáticas, objetos e outros autores) aderem?; como se transformam, como impactam em solo brasileiro?; e, além de tudo - o que era fundamental, uma espécie de pergunta-síntese colocada em nosso horizonte imediato -, como servem à compreensão da cultura comunicacional brasileira?; como demandam e como se deixam demandar por ela?

Esse leque de questões - e elas, de fato, compunham a problematização da pesquisa, naquele momento - acabava caracterizando o projeto como um estudo atípico sobre história das ideias, sobre a recepção local de uma macrovertente de reflexões umbilicalmente ligada ao continente europeu.

Não se pode esquecer - nem omitir - que o plano de trabalho previa também, numa etapa de encaminhamentos, a realização de descidas ao campo, aplicações práticas, que pudessem ensaiar, sob uma certa vigilância sócio-antropológica, apropriações desses marcos teóricos para pensar a história das mídias (ou para além da história das mídias, ou em contraponto à história das mídias) em nosso país. Esses casos empíricos, como é comum acontecer, encontravam-se em aberto - eram indefinições e fantasmas epistemológicos -, não estavam, de todo modo, nomeados na primeira formulação oficial do projeto de estudos.

O que propúnhamos não era apenas um mapa, é bom que fique claro. Era um mapa orientado à identificação de uma cor local e à instrução de uma prática analítica. Um mapa para extração de posições epistêmicas, como subsídio para a confecção de uma série de ensaios multissituados. A tese de Luis Fernando Rabello Borges (2019), que eu havia orientado, era, à minha volta, uma pista e uma inspiração.

Venho nutrindo esse interesse teórico pela arqueologia das mídias desde, pelo menos, 2010, muito embora não tivesse adquirido ainda nenhum tipo de comprometimento formal (ou, para dizer de outra forma, nenhum tipo de comprometimento tão direto ou tão frontal) com o assunto ${ }^{3}$. Autores como Friedrich

\footnotetext{
${ }^{3}$ A raíz desse interesse remonta a uma comunicação realizada no âmbito da Compós Associação Nacional dos Programas de Pós-Graduação em Comunicação-, em 2002, a partir da elaboração de um ângulo presente em minha tese de doutorado (SILVEIRA, 2002). À época, porém, não havia uma rubrica teórica sedimentada, a qual eu pudesse me filiar. Na ausência de uma "escola" - ou de um conjunto identificável de referências, um corpo de autores trabalhando em conjunto, com uma articulação programática mínima - eu podia operar numa
} 


\section{VOZES $_{\text {\&IÁLORO }}^{\mid}$}

Itajaí, V. 20, n.01, jan-jun 2021

Kittler, Jussi Parikka e Michael Goddard - para citar alguns dos formuladores e divulgadores mais originais - vão aparecer em meus textos, convertidos em operadores teóricos, por volta de 2014 (SILVEIRA, 2014). Esse é também o momento em que parece ter ocorrido, entre nós, um primeiro pico de interesse por essa perspectiva de estudos, evidenciado através de uma primeira onda mais reconhecível (embora ainda tímida) de publicações de autores brasileiros, dentre os quais me incluo, em fóruns e revistas da área da Comunicação no Brasil.

Minha disposição singular, até então, era a disposição genuína de um professor de Teorias da Comunicação, um professor curioso que, quase por coincidência (mas também por teimosia), faz pesquisa, mantendo-se numa luta inglória contra o sequestro do tempo de que dispõe, um professor que pesquisa para dar conta de suas aulas, para qualificar suas aulas ou para atualizar-se, para ampliar um repertório de informações teóricas (que lhe agrada cultivar). É óbvio que esses âmbitos (essas duas práticas: dar aulas e fazer pesquisa) estão amalgamados. Em nosso cotidiano vivido são indissociáveis. Quero salientar, no entanto, que a(s) arqueologia(s) da mídia figurava(m), até então, como um tipo de contrabando, um acessório secundário, um produto adquirido a granel, no contexto de sucessivos projetos de pesquisa (dois, no mínimo [desde 2010]), cujos núcleos, cujos comprometimentos maiores e mais formais, em termos teóricos (porém, não só), residiam noutro lugar, seja na estética, seja nas materialidades da comunicação, seja numa fluída antropologia da comunicação urbana, requalificada por um cacoete benjaminiano nítido e franco, embora nem sempre dominante (SILVEIRA, 2002, 2004).

Hans U. Gumbrecht (1999, 2014, 2015) e Mark Fisher (2009, 2014, 2016a, 2016b, 2018a, 2018b, 2018c, 2019) foram os autores com os quais mais me envolvi nos últimos dez ou doze anos. Chego aos mídia-arqueólogos conduzido por eles - ou por intermédio deles. Gumbrecht me empurrara nessa direção em virtude de suas explorações mediais, da maneira como considera a técnica e os efeitos de presença produzidos por diversos fenômenos sociológicos (dentre eles, fenômenos midiáticos, a beleza atlética encontrada no esporte, a própria literatura). Fisher contribuiu, no mesmo sentido, por haver me chamado a atenção para o consumo da cultura pop como consumo nostálgico, por compartilhar comigo uma sensação (um índice geracional, é bem provável) de ausência de futuro, de que melancolia e repetição parecem ter se afirmado, nas duas últimas décadas, como traço, signo e sintoma muito emblemáticos da música pop - e, muito mais amplo do que ela, emblemáticos de um largo processo de "modernização popular" e hiperespetacularização generalizada da vida social.

Os dois autores, cada um do seu jeito, buscam compreender as inúmeras figuras do tempo que hoje nos assolam, com as quais convivemos, aos sustos, sem norte: o passado recolocado (como um espectro), o futuro bloqueado, o presente evanescente (um líquido), 


\section{VOZES $_{\text {\&IÁLORO }}^{\mid}$}

Itajaí, V. 20, n.01, jan-jun 2021

as histórias alternativas, o retrofuturismo (o novo sendo encontrado no seio do antigo), a sobressaturação da memória, o curso histórico como loop interminável, o irrompimento ilusório de um déjà-vu. É dentro dessa moldura, é com essa cadeia de deslizamentos e consequências, para chamá-las de algum modo, que me movimento rumo à arqueologia das mídias.

Conforme me aproximo, no entanto - e aqui reside o impasse acima anunciado, devo explicá-lo -, tenho a percepção de que o campo mídia-arqueológico, apesar de sua riqueza, apesar de se colocar com naturalidade nesse encadeamento progressivo de interesses que se atraem (e que me atraem), estaria ainda carecendo, no Brasil, de um maior lastro, de um maior contingente de produtos, de maior fortuna crítica, de bases enfim mais concretas, para que eu pudesse lhes dedicar, só assim, um mapeamento ${ }^{4}$. O que questiono não é a qualidade desses estudos, é claro (embora essa crítica possa também ser feita, quando oportuna). Não é também sua quantidade absoluta. Antes, é sua diversidade interna, sua dispersão (bem como sua continuidade) no tempo e sua capacidade de se apresentar como (um conjunto ou) uma "mancha" mais regular, mais entranhada, mais densa e persistente.

Um parêntese - apenas para ilustrar. Um exame das cem primeiras ocorrências relativas ao tema "arqueologia das mídias" no Google Acadêmico, cobrindo o período de 2000 a 2020, nos permite fazer algumas inferências. O escrito mais antigo remete a 2002. É um texto de Irene Machado, reportando ao curso dado pelo professor Siegfried Zielinski, do Kunsthochschule für Medien Köln (Academia de Artes e Mídia), de Colônia (Alemanha), aos pesquisadores do Programa de Pós-Graduação em Comunicação e Semiótica da PUC / SP, no mês de agosto de 2001. Desse curso derivou o livro de Zielinski, Arqueologia da Mídia: em busca do tempo remoto das técnicas do ver e do ouvir (Annablume, 2006), até hoje o marco fundacional desse campo de estudos no país 5 .

\footnotetext{
${ }^{4}$ Uma versão desse mapeamento introdutório foi elaborada numa publicação anterior (SILVEIRA, 2020a). E há outros estudos que se prestam aos mesmos propósitos (TELLES, 2019a, 2019b, 2019c, 2017; PEREIRA, BELEZA e AZEVEDO, 2020). Vale consultá-los.

${ }^{5}$ Outros eventos pioneiros, de peso fundacional, foram: 1) o curso de extensão promovido pelo Núcleo de Pesquisa Semiótica Crítica, coordenado pelo prof. Dr. Alexandre Rocha da Silva, junto à Universidade Federal do Rio Grande do Sul, em 2015 - esse curso teve edições subsequentes, em 2016 e 2020; 2) a edição n. 14 da revista TECCOCS - Revista Digital de Tecnologias Cognitivas, lançada em julho de 2016, junto ao Programa de Tecnologias da Inteligência e Design Digital da Pontifícia Universidade Católica de São Paulo; e 3) a Revista IHU-OnLine, editada pela Universidade do Vale do Rio dos Sinos, em São Leopoldo / RS, em 2011. Dentre as publicações, ganha destaque o livro A(na)rqueologias das Mídias, organizado por Marcelo Bergamin Conter e Jamer Guterres de Melo (2017). Esses eventos, com seus desdobramentos, já foram referidos numa outra oportunidade (SILVEIRA, 2020a).
} 


\section{VOZES \\ DIÁLORO}

Itajaí, V. 20, n.01, jan-jun 2021

O que temos, a partir daí, são trabalhos que exploram, majoritariamente, três intersecções: 1) com os estudos de games, 2) com os estudos de música e sonoridades e 3) com os estudos sobre audiovisual (cinema, televisão, fotografia e cinema de animação, nessa ordem). Entre 2000 e 2005, há registros de quatro trabalhos; outros quatro entre 2006 e 2010; oito entre 2011 e 2015; e a grande maioria, cinquenta e quatro, nos últimos cinco anos, de 2016 para cá. Esse marco teórico suscita também discussões em outras disciplinas, tais como a Literatura Comparada, a Arquivística (ou Arquivologia), as Humanidades Digitais, Memória e Patrimônio e a própria Antropologia.

Excetuando-se as repetições, excetuando-se três ou quatro referências muito isoladas - uma dissertação sobre arqueologia subaquática, por exemplo - essas cem ocorrências nos permitem enxergar o campo se constituindo. Nominalmente, vemos a ascendência dos nomes de Zielinski, Kittler e Parikka sobre os demais, com Thomas Elsaesser ganhando terreno nos últimos três anos, a partir da publicação, no Brasil, de dois de seus livros. Há um único texto de Wolfgang Ernst (2019), "Sobre a sonicidade”, traduzido por Eduardo Luersen, e nenhum artigo específico de ou sobre Kluitenberg.

Uma filtragem mais rigorosa - excluindo-se menções a livros publicados, pequenas resenhas e comunicações breves, teses e dissertações disponibilizadas na íntegra, aplicações em disciplinas circunvizinhas - nos faria selecionar 29 artigos publicados em periódicos acadêmicos ou em fóruns especializados no Brasil. É pouco? Como avaliar esse número? Fecha parêntese.

O que tenho feito, portanto, é produzir nas bordas da arqueologia da mídia, catando ali motivadores teóricos, pinçando leituras, ensaiando novas entradas. Talvez isso explique o fato de que nas duas últimas incursões que fiz, nas transições de 2017 para 2018 e de 2018 para 2019, nas duas "largadas" do projeto de pesquisa (feito e refeito), tenha retornado de lá com experiências literárias, explorações metodológicas transversais (primeiro, Gigante Figura [2018] ${ }^{6}$; depois, Mecanosfera / Monoambiente [2020] ${ }^{7}$ - dois

\footnotetext{
${ }^{6}$ Gigante Figura é uma ficção steampunk, uma história alternativa, poderíamos dizer. E pode ser lido como um estudo mídia-arqueológico. Recebeu indicação para o Prêmio AGES Associação Gaúcha de Escritores, em 2019, na categoria Especial. Já foi apresentado e discutido nos seguintes eventos acadêmicos: A) XIV Seminário Internacional de Comunicação, 2017, na PUCRS; B) Sessão de relatos de pesquisa, 2018, na Univates / RS; C) Encontro Arredores da Imagem, 2018, na Universidade Federal do Rio Grande do Sul; D) I Seminário Discente PPGCCom, 2018, na Unisinos / RS; E) III Colóquio Internacional de Investigação Crítica em Comunicação, 2018, na Unisinos / RS; F) II Encontro Internacional SDISCON - Estudos semióticos, gêneros discursivos e ensino na contemporaneidade, 2019, na Universidade Estadual do Amazonas (UEA).

${ }^{7}$ Mecanosfera / Monoambiente é um experimento de escrita, hibridiza a novela e o ensaio teórico, autoteoria e autofiç̧ão. Foi lançado em setembro de 2020 pela editora Zouk, de Porto Alegre / RS.
} 


\section{VOZES $_{\text {\&IÁLORO }}^{\mid}$}

Itajaí, V. 20, n.01, jan-jun 2021

livros decorrentes do contato com a hipótese das mídias imaginárias, aventada por Eric Kluitenberg [2016]).

Ou seja: tenho orbitado esse campo, sem aterrissar nele. Tenho me mantido num "limiar”, numa tangente, numa “zona de fricções”. É aí que se encontram - nessa minha perspectiva - os livros de Mark Fisher. É aí que se encontram o tema da ficção teórica e o conceito de hiperstição, que me absorveram sobremaneira em 2020 (SILVEIRA, 2020b, 2020c). Qual é, enfim, o dilema? Devo aferrar-me ao espaço de borda onde me encontro (com algo de Gumbrecht; com Fisher, sobretudo; e com referências mais vagas, uma atenção flutuante aos mídia-arqueólogos europeus que antes citei)? Devo tirar maior proveito dos escritos que já produzi até aqui, dos investimentos recentes que fiz, desde o começo do projeto (nessa versão), ou devo respirar fundo e renovar os ânimos, mais uma vez, para mergulhar no riacho de águas (ainda) calmas da arqueologia das mídias?

\section{2.}

Minha tendência, no momento, é ir potencializando - em oportunidades como essa, em periódicos e fóruns da área, no futuro imediato - um giro reflexivo, a singularização de um novo foco sobre um fundo teórico-temático que permanecerá inalterado. Passariam a ganhar destaque as ficções teóricas, compreendidas aqui amplamente, como conjunto de formas textuais (por hipótese, um gênero discursivo, entre a ciência e a literatura), como dispositivo metodológico (um dispositivo de invenção e crítica de métodos observacionais e formas narrativas), como núcleo de um debate epistêmico (caro à epistemologia da Comunicação, com certeza) e como categoria teórica a ser aprofundada.

Ficções teóricas, como sustentei em outras oportunidades (SILVEIRA, 2020a, 2020b, 2020c), não são estranhas às reflexões de Mark Fisher e Hans U. Gumbrecht. Não são alheias a setores delimitados da arqueologia das mídias (aqui, o nome de Kluitenberg vem outra vez à tona). Não são estranhas nem mesmo aos estudos de mídia. O tema, entretanto, continua pouco tratado. Esse é um fator atraente.

Um ajuste de foco, por certo, não se fará sem alguns cuidados. O primeiro deles diz respeito à manutenção da rubrica formal nos registros administrativos da universidade, posto que eventuais alterações (internas, no domínio epistêmico [dentro do universo diegético, se isto fosse uma obra ficcional]) não irão configurar a abertura de um novo processo ou a inscrição de um novo projeto de pesquisa.

O segundo diz respeito ao redimensionamento do plano de estudos no tempo, montando-se, para ele, uma estrutura modular, com etapas muito bem definidas, muito bem distribuídas no calendário, com suas metas relativas, de modo que possamos, atingindo os objetivos mais próximos, avançar de modo regulado. Um cronograma (re)planejado nos permitirá cumprir, ao fim, objetivos maiores e obter uma produção mais abrangente, mais orgânica e integralizada. Há que se ter em conta, nesse particular, a 


\section{VOZES $_{\text {\&IÁLORO }}^{\mid}$}

Itajaí, V. 20, n.01, jan-jun 2021

natureza de um estágio pós-doutoral, cuja finalidade não é a confecção e a defesa de uma tese, perante uma banca, mas é fomentar uma atualização, a qualificação da produção bibliográfica e otimizar ações de caráter didático-pedagógico, tendo em vista (a inserção e) as atividades futuras do pesquisador.

O terceiro cuidado diz respeito ao grupo de pesquisa, reposicionando os novos compromissos (as questões a serem trazidas, as discussões implementadas, o novo leque de leituras) em articulação ao mesmo conjunto de investigações simultâneas e paralelas em que hoje me coloco ${ }^{8}$.

O quarto cuidado/compromisso - e que, evidentemente, garantirá o cumprimento dos demais, tendo em vista que também decorre deles, decorre especialmente do primeiro e do terceiro - é problematizar positivamente a comensurabilidade desses "paradigmas", para chamá-los assim - arqueologia das mídias + ficções teóricas -, isto é, sua pertinência cruzada, a regularidade aceitável da oscilação que vislumbramos, afinando-se os passos já dados e o espaço de trabalho já constituído à sequência replanejada para a investigação.

"Incomensurabilidade" é um termo corrente no debate epistemológico (SILVEIRA, 2019). Tanto Thomas Kuhn (1989) quanto Paul Feyerabend (2011, 2016) o utilizam (MELOGNO, 2017). Quando o fazem, os dois estão refletindo sobre a compatibilidade (ou a incompatibilidade, no caso) dos paradigmas científicos em disputa, num mesmo domínio científico, num mesmo contexto sócio-histórico. A incomensurabilidade se manifestaria em graus (ou níveis) e em estratos distintos. Segundo Kuhn, há incomensurabilidade de princípios, de termos e de modos de vero mundo. Para ele, mais atento à história do que aos métodos das ciências, a imposição de um paradigma sobre outro implica sempre uma conversão (há sempre algo de súbito, da ordem de uma adesão irracional) e uma elevada taxa de incomensurabilidade.

Embora tenha questionado a existência histórica efetiva de algo como a "ciência normal” - uma conhecida definição kuhniana -, Feyerabend compartilha com ele o reconhecimento de que, sim, o progresso científico é o transcurso avassalador (e imparável) das alterações teóricas. Essas alterações do repertório teórico, porém, são também “mudanças de mundo", diz ele. Não são apenas mudanças de caráter semântico ou epistemológico, restritas à ciência. Para Feyerabend, são dissonâncias ou estremecimentos ontológicos muito maiores. O mundo inteiro se torna outro, a linguagem instrumental e cotidiana (além da própria linguagem científica, é claro) se vêem alterados. As cosmologias que daí se depreendem se tornam intraduzíveis. Feyerabend, em suma, é mais universalista e menos "epistemocêntrico" do que Kuhn.

\footnotetext{
${ }^{8}$ O grupo Corporalidades é um dos Núcleos de Pesquisa integrantes do GPESC - Grupo de Pesquisa em Semiótica e Culturas da Comunicação, que atua junto ao PPGCom / UFRGS, desde 2010. Os encontros ocorrem, no mínimo, duas vezes por mês, durante os semestres letivos, e reúnem estudantes em diversos níveis de formação, iniciação, mestrado, doutorado e pós-doutorado. É um espaço onde as pesquisas individuais são apresentadas e debatidas, onde textos teóricos e metodológicos úteis às investigações em curso também são lidos e discutidos.
} 


\section{VOZES $_{\text {\&IÁLORO }}^{\mid}$}

Itajaí, V. 20, n.01, jan-jun 2021

Para que nos serve tudo isso? Primeiro, porque seguir a trilha das ficções teóricas - como viemos fazendo - não ocorrerá em segurança sem o amparo da filosofia da ciência. O debate, em si, é um debate de fundo epistêmico. Segundo, porque o "anarquismo epistemológico" de Feyerabend é também um pluralismo crítico, que nega à ciência e à racionalidade a tutela do conhecimento ou a exclusividade no que toca à definição da verdade, à indicação e ao alcance de uma vida boa. Terceiro, porque arqueologia da mídia e theory fiction sequer são paradigmas, são teorias locais, de alcance restrito e, num certo sentido, não rivalizam, são próximas (ou francamente aproximáveis). Entre elas, há espaços de sobreposição e de encontros. Há vasos comunicantes e filtros tradutórios. É possível pensá-las, portanto, num campo teórico ampliado, rastrear suas linhas de continuidade. É nesse terreno que iremos atuar.

\section{3.}

Mas o que é - já que tanto insisto nisso - uma ficção teórica? Um bom ponto de partida nos é dado por Gregory Marks (2018). Para ele, são entrelaçamentos experimentais entre teoria e ficção, são exercícios de diluição dessas fronteiras. Por um lado, a teoria é retirada de seu pedestal e dessacralizada; por outro, afirmam-se os poderes proféticos e a sensualidade da ficção. Muitos desses textos - nos diz o autor - são motivados por sensações de frustração, de incompletude, de descontentamento, de suspeita em relação às instituições, aos modos de saber e às práticas narrativas estabelecidas. Mais do que um gênero discursivo, no entanto, uma ficção teórica seria, antes de tudo, uma atitude.

É importante observar, além do esboço conceitual, a lista de leituras apresentada por Marks. Cem livros são relacionados - é uma lista extensa - e chama atenção também o modo como esses escritos são agrupados. De uma parte, temos especulações teóricas que se apropriam de formas literárias (em termos de estilística, de poética e de filiação a um gênero). Por exemplo: Rua de Mão Única, de Walter Benjamin ([1928] 1987), Minima Moralia, de Theodor Adorno ([1951] 2008), Velocidade e Política, de Paul Virilio ([1977] 1996), Mil Platôs, de Gilles Deleuze e Felix Guattari ([1980] 1995). De outra parte, há peças ficcionais se apropriando do tom professoral e dos conteúdos teóricos, como "Durante a construção da Muralha da China”, de Franz Kafka ([1918] 2002), As Cidades Invisíveis, de Ítalo Calvino ([1972] 1990), Eu Amo Dick, de Chris Kraus ([1997] 2019), e Os Anéis de Saturno, de W.G. Sebald (1995). Entre esses dois extremos, Marks faz questão de salientar, há variações maiores, formatos ainda mais estranhos, híbridos e indisciplinados, versos, textos íntimos, textos confessionais, dramaturgia, ficção científica e ciência inventada.

É possível achar um sentido mais estrito e uma discussão mais profunda a respeito em Flatline Constructs. Gothic materialism and cybernetic theory-fiction, a tese de doutoramento de Mark Fisher, defendida junto à Universidade de Warwick (UK), em 


\section{VOZES $_{\text {\&IÁLORO }}^{\mid}$}

Itajaí, V. 20, n.01, jan-jun 2021

1999. Um detalhe: o trabalho só foi publicado no ano seguinte à morte do autor (FISHER, 2018).

Assombrado pelos rumores do Bug do Milênio $^{9}$, Fisher recorre ao pensamento francês do final da década de 1960 - o pós-estruturalismo, o germe do chamado "pósmoderno" e a psicanálise - como suporte para investigar nosso ingresso claudicante no século XXI. O que propõe, em síntese, é uma filosofia da cibercultura, amparada fortemente em Jean Baudrillard, Freud lido por Lacan, Gilles Deleuze e Félix Guattari.

A paisagem cultural na qual o autor mergulha - que é trazida e dissecada por ele, no transcurso da tese - é povoada por livros como Neuromancere Count Zero, de William Gibson (1984, 1986), Atrocity Exhibition e Crash, de J.G. Ballard (1969, 1973), filmes como In The Mouth of Madness, de John Carpenter (EUA, 1994), Blade Runner, de Ridley Scott (EUA, 1982), e Videodrome, de David Cronenberg (Canadá, 1983). O que ele produz, ao examinar esses materiais, é a constatação de que, no ciberespaço - ou num mundo cuja epiderme medial se encontra endurecida, mais espessa -, a realidade já não é mais representada, não se deixa nem se pode mais fazer representar. E não só isso: ela teria se revestido de uma "estranheza onírica”.

Gothic flatline, um dos eixos articuladores do estudo, tal como Fisher o estrutura, irá aludir a isso: a uma zona de imanência radical, um plano onde não é mais possível diferenciar o animado do inanimado. Um plano onde possuir agência não significa estar vivo. Não necessariamente. Que papel, afinal de contas, resta à consciência e à ação humanas quando o protagonismo passou aos modelos inorgânicos, aos fluxos informacionais, à reprodução mecânica, aos sistemas de hipercontrole e à propagação viral? O problema é enorme.

Transcendência versus imanência, imaterialidade versus materialidade, animismo versus maquinismo, orgânico versus inorgânico, vitalismo versus mecanicismo, irrealismo versus realismo. Esses são os pólos que o autor problematiza, distencionando-os, encurtando-os, observando como se refazem, deixando que se esvaziem ou que percam a razão de ser. A emergência de uma cultura tecnologizada, na esteira do infocapitalismo global, impacta nossos esquemas perceptuais, é inegável. Instala-se uma flutuação entre o imaginário e o hiper-real: um estaria convocando o outro, num trânsito contínuo e envolvente. A licantropia, o vampirismo, o zumbi, o autômato, o robô e as máquinas cibernéticas, nesse cenário, se tornam temáticas combináveis, atinentes aos modos de simulação que presidem a nova organização e as novas dinâmicas societais.

\footnotetext{
${ }^{9}$ Dois comentários tangenciais: teorias conspiratórias, rumores e boatos, como esse do Bug do Milênio, independentemente de sua posterior confirmação ou não, quando se apresentam, são ficções teóricas, são hiperstições, como definimos num artigo anterior (SILVEIRA, 2020c); depois de vinte anos, voltar à tese de Mark Fisher, disponível no repositório digital da Universidade de Warwick - http://wrap.warwick.ac.uk/110900/1/WRAP_Theses_Fisher_1999.pdf -, é como entrar no túnel do tempo. É ser acometido por uma febre nostálgica. É uma verdadeira expedição mídia-arqueológica.
} 


\section{VOZES

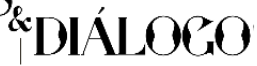

Itajaí, V. 20, n.01, jan-jun 2021

Torna-se apropriada, portanto - como julga Fisher -, a recuperação das proposições de Jean Baudrillard - um filósofo que já foi chamado, noutro livro, de "póshumanista fáustico" e "tecnófobo esotérico" (RUDIGER, 2007). São emblemáticas suas discussões sobre simulacro e simulação $^{10}$, por exemplo. Ele chega a falar numa “autonomização do mundo das imagens”, como se as simulações precedessem (e, em alguma medida, produzissem) o real, tendo, sobre ele, implicações dramáticas.

Sendo correto esse diagnóstico - Fisher se pergunta -, por que razão a produção teórica e o pensamento acadêmico deveriam se manter imunes e/ou intactos? As cybernetic theory-fictions não seriam as melhores tradutoras do materialismo gótico (gothic flatline)? Os livros de Gibson e Ballard não são, eles mesmos, expressões de um pensamento conceitual de novo tipo?

O que se coloca em causa quando aceitamos esses pressupostos é um redimensionamento da artificialidade, não só do ponto de vista epistêmico, mas do ponto de vista de sua funcionalidade. Os sistemas teóricos não visam mais a uma transcendência. Trata-se, a partir de agora, de multiplicar os signos e acelerar os jogos de simulação. $\mathrm{O}$ discurso teórico não mimetiza, não representa e não esmiuça a realidade, mas se coloca num processo de agência em relação a ela. Discursos explicativos e mundos artificiais passam a formar um único rizoma. Ocupam um mesmo plano de imanência. São apanhados num circuito de feedbacks, contaminando-se reciprocamente.

Feito esse giro, resta refazê-lo com atenção redobrada, justificando boas escolhas empíricas e refinando, acima de tudo, o debate teórico que dará rumo à investigação. Afinal, como diz Fisher (2018: 142), de modo sugestivo, nos deparamos com "a superficie plana de um espelho negro”.

\section{Bibliografia}

ADORNO, Theodor. Minima Moralia. Reflexões a partir da vida lesada. Rio de Janeiro, Azougue, 2008.

\footnotetext{
${ }^{10}$ Para Baudrillard $(1991,1996)$, existem três tipos de simulacros: 1. simulacros naturais, naturalistas, baseados na imagem, na imitação e no fingimento; são operáticos (ou operísticos), de estatuto teatral; 2 . simulacros produtivos, produtivistas, baseados na energia, na força, na sua materialização pela máquina e em todo o sistema de produção; são operatórios, de estatuto industrial; 3. simulacros de simulação, baseados na informação, no modelo, no jogo cibernético; são operacionais, de estatuto cibernético. Em ordem, teríamos: um imaginário da utopia, um imaginário da ficção científica e o imaginário de uma implosão, de uma ultrapassagem do real - a "predecessão do modelo". Mark Fisher problematiza os simulacros de terceira ordem. É a partir daí que ele avança.
} 


\section{VOZES $_{\text {\&IÁLORO }}^{\mid}$}

Itajaí, V. 20, n.01, jan-jun 2027

BAUDRILLARD, Jean. Simulacros e Simulação. Lisboa: Relógio D’Água, 1991. . A Troca Simbólica e a Morte. São Paulo: Loyola, 1996.

BENJAMIN, Walter. Rua de Mão Única. São Paulo: Brasiliense, 1987.

BORGES, Luis Fernando Rabello. Cultura digital e tecnologias musicais antecipadas na revista SomTrês. Programa de Pós-Graduação em Ciências da Comunicação da Universidade do Vale do Rio dos Sinos, Unisinos. São Leopoldo, 2019. Tese de Doutorado. Cópia fornecida pelo autor.

CALVINO, Ítalo. As Cidades Invisíveis. São Paulo: Cia. das Letras, 1990.

CONTER, Marcelo; MELO, Jamer Guterres (orgs.). A(na)rqueologias das Mídias. Curitiba - PR: Editora Appris, 2017.

DELEUZE, Gilles; GUATTARI, Félix. Mil Platôs. Capitalismo e esquizofrenia. Volume I. Rio de Janeiro: Editora 34, 1995.

ELSAESSER, Thomas. Cinema como Arqueologia das Mídias. São Paulo: Edições Sesc, 2018.

ELSAESSER, Thomas; HAGENER, Malte. Teoria do Cinema. Uma introdução através dos sentidos. Campinas: Papirus, 2018.

ERNST, Wolfgang. Media Archaeography: Method and Machine versus History and Narrative of Media. In: Huhtamo, E. \& Parikka, J. (orgs). Media Archeology: Approaches, Applications, and Implications. Berkeley, California: University of California Press. 2011.

. Digital Memory and the Archive. Minneapolis University of Minnesota Press, 2013.

- Sobre a sonicidade. Tradução de Eduardo Harry Luersen. Revista GEMInIS, São Carlos, UFSCar, v. 10, n. 1, pp.4-26, jan./abr. 2019.

FELINTO, Erick. Em busca do tempo perdido: o seqüestro da história na cibercultura e os desafios da Teoria da Mídia. Revista Matrizes, Ano 4 - no 2 jan./jun. 2011, São Paulo, Brasil, p. 43-55, 2011.

. Um futuro complexo, híbrido, incerto e heterogêneo. IHU-Online, $\mathrm{n}^{\mathrm{o}}$

375, ano XI. Entrevista concedida para Márcia Junges e Thamiris Magalhães. Disponível em

<http://www.ihuonline.unisinos.br/index.php?option=com_content\&view=article\&id=410

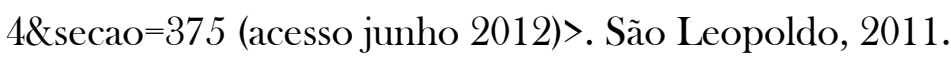

Novos materialismos, realismo especulativo e comunicologia: sobre algumas proposições para as ciências humanas em diálogos com as artes e tecnologias contemporâneas. In: PEREIRA, Vinicius Andrade; CASTELLARI, Arturo Colorado (orgs.). ARTECNOLOGIA: Arte, Tecnologia e Linguagens Midiáticas. Porto Alegre: Buqui, 2013. 


\section{VOZES $_{\text {\&IÁLORO }}^{\mid}$}

Itajaí, V. 20, n.01, jan-jun 2021

_. Zona Cinzenta: imaginação e epistemologia fabulatória em Vilém Flusser. In: FELINTO, Erick; MÜLLER, Adalberto; MAIA, Alessandra (orgs.). A Vida Secreta dos Objetos: Ecologias da Mídia. 1ed. Rio de Janeiro: Azougue, 2016, v. 1, p. 11-27.

FEYERABEND, Paul. Contra o Método. São Paulo: UNESP, 2011.

Ciência, um Monstro. Belo Horizonte: Autêntica, 2016.

FISCHER, Gustavo. Arqueologia e genealogia das mídias, uma articulação necessária. Revista IHU-OnLine. UNISINOS. Número 375, Outubro 2011.

FISHER, Mark. Capitalist Realism. Is there no alternative? Winchester - UK; Washington - EUA: Zero Books, 2009.

Ghosts of My Life. Writings on depression, hauntology and lost futures. Winchester - UK; Washington - EUA: Zero Books, 2014. The Weird and the Eerie. London: Repeater, 2016a.

Realismo Capitalista. No hay alternativa? Buenos Aires: Caja Negra Editorial, 2016b.

Los Fantasmas de Mi Vida. Escritos sobre depresión, hauntología y futuros perdidos. Buenos Aires: Caja Negra, 2018a.

Flatline Constructs. Gothic materialism and cybernetic theory-fiction. New York: Exmilitary, 2018b.

Lo Raro y Lo Espeluznante. Barcelona: Alpha Decay, 2018c.

K-Punk. Escritos reunidos e inéditos (libros, películas y televisión). Buenos Aires: Caja Negra, 2019.

FISHER, Mark; AMBROSE, Darren (eds.). K-Punk: the collected and unpublished writings of Mark Fisher (2004-2016). Londres: Repeater, 2018.

GODDARD, Michael. Opening up the black boxes: media archaeology, 'anarchaeology' and media materiality. New Media \& Society, v. 17, n. 11, p. 1-16, 2015.

GUMBRECHT, Hans Ulrich. Em 1926: vivendo no limite do tempo. Rio de Janeiro: Record, 1999.

Depois de 1945. Latência como origem do presente. São Paulo: UNESP, 2014 .

Nosso Amplo Presente. O tempo e a cultura contemporânea. São Paulo: UNESP, 2015.

HERTZ, Garnet; PARIKKA, Jussi. Mídia zumbi: desvio de circuito da arqueologia da mídia para um método de arte. TECCOGS: Revista Digital de Tecnologias Cognitivas, TIDD | PUC-SP, São Paulo, n. 14, p. 98-113, jul-dez. 2016.

HUHTAMO, Erkki. Pockets of Plenty: An Archaeology of Mobile Media. In: RIESER, Martin (ed.). The Mobile Audience: Media Art and Mobile Technologies. Amsterdam/New York: Rodopi, 2011. 


\section{VOZES $_{\text {\&IÁLORO }}^{\mid}$}

Itajaí, V. 20, n.01, jan-jun 2021

. Dismantling the fairy engine: Media archaeology as topos study. In:

HUHTAMO, E. \& PARIKKA, J. (eds.). Media Archaeology: approaches, applications, and implications (27-47). Berkeley: University of California Press, 2011.

. From Kaleidoscomaniac to Cybernerd: notes toward na archaeology of the media. Leonardo, v. 30, 3/1997. Disponível em <http://goo.gl/KjtQqz> Acesso em: 1 abr. 2015 .

HUHTAMO, Erkki;JUSSI, Parikka. Media Archeology: approaches, applications, and implications. Berkeley: University of California Press. 2011.

KAFKA, Franz. Durante a construção da muralha da China. In: KAFKA, Franz. Narrativas do Espólio (1914-1924). São Paulo: Cia. das Letras, 2002.

KITTLER, Friedrich. Discourse Networks, 1800/1900. Stanford, CA: Stanford University Press, 1990.

. Gramophone, Film, Typewriter. Stanford: Stanford University Press, 1999.

KLUITENBERG, Eric. Sobre a arte das mídias imaginárias. TECCOGS: Revista Digital de Tecnologias Cognitivas, TIDD | PUC-SP, São Paulo, n.14, p. 137-150, jul-dez. 2016.

KRAUS, Chris. Eu Amo Dick. São Paulo: Todavia, 2019.

KUHN, Thomas. A Estrutura das Revoluções Científicas. São Paulo: Perspectiva, 1989.

MARKS, Gregory. A theory-fiction reading list. The Waste World. Gothic past and post-human futures. https://thewastedworld.wordpress.com/2018/11/03/a-theoryfiction-reading-list. Postado em 03 de novembro de 2018. Acessado em 26 de janeiro de 2019.

MELOGNO, Pablo. Divergentes: Kuhn, Feyerabend, inconmensurabilidad y sentido crítico. In: CAMEJO, M.; GIRI, L.; MIGUEL, H. (comps.). Ciencia, Tecnología y Educación: miradas desde la filosofía de la ciencia. Montevideo: Byblos, 2017, pp. 141163.

PARIKKA, Jussi. Digital Contagions: a media archaeology of computer viruses. New York: Peter Lang, 2007.

. What is Media Archeology? Cambridge: Polity Press, 2012.

. Arqueologia da mídia: interrogando o novo na artemídia. Intexto, Porto Alegre, UFRGS, n. 39, p. 201-214, maio/ago., 2017.

PEREIRA, Cláudia; BELEZA, Joana; AZEVEDO, Marcella. As “coisas” em seus devidos lugares: as materialidades no campo da Comunicação e do Consumo. E-Compós, v. 23, 24 jan. 2020 .

RÜDIGER, Francisco. Introdução às Teorias da Cibercultura. Porto Alegre: Sulina, 2007. 


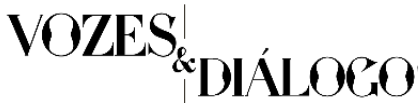

Itajaí, V. 20, n.01, jan-jun 2021

. O passado pode nos ensinar a seu próprio respeito. Revista IHUOnLine. UNISINOS. Número 375, Outubro 2011.

SEBALD, Winfried Georg. Os Anéis de Saturno. Rio de Janeiro: Record, 2002.

SILVEIRA, Fabrício. O parque dos objetos mortos: por uma arqueologia da materialidade das mídias. In: ENCONTRO ANUAL DA COMPÓS, 2002, Rio de Janeiro. Anais... Rio de Janeiro: Universidade Federal do Rio de Janeiro, 2002.

. O televisor na visualidade das vitrines: comunicação, consumo e cultura material. In: ENCONTRO ANUAL DA COMPÓS, 2004, São Paulo. Anais... São Paulo: Universidade Metodista de São Paulo, 2004.

- Arqueologia da mídia: preocupação com os estudos da técnica. Revista IHU-OnLine. UNISINOS. Número 375, Outubro 2011.

. Arqueologia do rock gaúcho. Um década de metal pesado em Santa Maria (1980-1990). In: DI PINTO, Charles; BORBA, Gustavo (orgs.). Fragmentos de Memória do Rock Gaúcho. São Leopoldo - RS: Ed. Unisinos, 2014, p. 19-49.

Música pop e guerra aérea. In: CONTER, Marcelo; MELO, Jamer Guterres (orgs.). A(na)rqueologias das Mídias. Curitiba - PR: Editora Appris, 2017, p. 77 92.

Gigante Figura. Porto Alegre: Riacho, 2018.

. Esse metal incandescente... O conceito de texto em Roland Barthes e a escrita de ficção como método. In: FEIL, Gabriel Sausen; OLIVEIRA, Marcos da Rocha; FEITOSA, Sara. T3xto. Assis: Triunfal Gráfica e Editora, 2019a, 247p.

. Incomensurabilidade semântica e mudança de mundo em Thomas Kuhn. Apontamentos iniciais para um projeto de pesquisa. Revista TROPOS: Comunicação, Sociedade e Cultura, Universidade Federal do Acre (UFAC), Rio Branco AC, v. 8, p. 01 - 13, dezembro, 2019b.

- Gigante Figura. Arqueologia das mídias, transficcionalidade e experimentação narrativa. In: ALMEIDA, Socorro Viana de; SOARES, Neiva Maria Machado (orgs.). Percursos Semióticos e Discursivos em Gêneros Contemporâneos. Rio de Janeiro: LetraCapital, 2020a, p. 53-70.

Mecanosfera / Monoambiente. Porto Alegre: Zouk, 2020b.

. Hiperstição e geotrauma em Cyclonopedia. Complicity with anonymous

materials, de Reza Negarestani. Trabalho apresentado no GP Teorias da Comunicação, XX Encontro dos Grupos de Pesquisas em Comunicação, evento componente do $43^{\circ}$ Congresso Brasileiro de Ciências da Comunicação, 2020c.

TELLES, Márcio. Medium/forma nas teorias alemãs das mídias: exterioridade, a priori tecnológico-medial, corporalidade, presença e Kulturtechnik. Verso \& Reverso, v. 31, p. 173-181, 2017. 


\section{VOZES $_{\text {\&IÁLORO }}^{\mid}$}

Itajaí, V. 20, n.01, jan-jun 2027

- Teoria Alemã das Mídias: geocomunicologia de um território

comunicacional. Programa de Pós-Graduação em Comunicação e Informação. Universidade Federal do Rio Grande do Sul, UFRGS, Brasil. Tese. 2019a.

- Des/Re/Escrevendo a história dos meios de comunicação: quatro contribuições a partir das arqueologias das mídias. Dispositiva, Belo Horizonte, v. 7, n. 12, p. 101-116, jan. 2019b.

- Mídia e história na Teoria Alemã das Mídias. Ação Midiática - Estudos em Comunicação, Sociedade e Cultura, p. 51-70, 2019c.

VIRILIO, Paul. Velocidade e Política. São Paulo: Estação da Liberdade, 1996.

ZIELINSKI, Siegfried. Audiovisions: cinema and Television as Entr'Actes in History. Amsterdam: Amsterdam. University Press. 356 p., 1999.

. Arqueologia da Mídia: em busca do tempo remoto das técnicas do ver e do ouvir. São Paulo: Annablume, 2006.

. Ser offline e existir online. Revista IHU-OnLine. UNISINOS. Número 375 , Outubro 2011. 